\title{
Designing for Cultural Values: Towards a Theory-motivated Method for Culture-sensitive Adaptation of Information Systems
}

\author{
Andreas Janson \\ University of St.Gallen \\ andreas.janson@unisg.ch
}

\author{
Ernestine Dickhaut \\ University of Kassel \\ ernestine.dickhaut@uni-kassel.de
}

\author{
Matthias Söllner \\ University of Kassel \\ soellner@uni-kassel.de
}

\begin{abstract}
To ensure that an intended target group accepts and uses an information system (IS) is a major challenge for service systems engineering and a key interest in IS research. On the one hand, individuals' cultural values affect their willingness to use an IS; on the other hand, information technology (IT) is neither value-neutral and, thus, also affects IT acceptance and usage. Therefore, the adaptation of IS should consider both sources of value. Thus, in this paper, we present the theory-driven design of a method for culturesensitive IS adaptation that draws on IT-culture conflict theory. Our two-fold evaluation approach results show that the method enables to create feasible results for developing culture-sensitive design solutions for IS. As a theoretical contribution, we contribute to the exploration of culture in IS development; as a practical contribution, we provide guidance in how to adapt IS for specific target groups.
\end{abstract}

\section{Introduction}

The aspect that information systems (IS) do not exist in isolation but are used in social and organizational contexts constitutes one of the major challenges in IS implementation projects. In this regard, IS research emphasizes the impact of individual differences such as contrasts in individuals' cultural values when considering IS implementation projects [1]. Since culture is a crucial factor in explaining how individuals interact and deal with information technology (IT) [2], understanding and considering the values of the target context in IS development and implementation projects become a decisive success factor for service systems engineering [3].

Distinct user groups have different value perceptions towards IT [4]. If a new IS does not coincide with the cultural values of the target context and the user group's IT values, it is likely to be rejected [2]. Thus, gaining share without cultural adaptation is a challenging task to undertake - an experience many companies make when transferring their IT products to foreign contexts, addressing a new user group [5-
7]. An example showing how important meeting the cultural values of the target group is to make a group finding favor in a product are the websites of Kentucky Fried Chicken (KFC) and Mc Donald's. Both websites provide diverse user experiences for western and Chinese consumers according to the target groups' shared values. Both western websites have a simple user interface and focus on their product range. From a western point of view, the Chinese websites are overloaded with information, have a complex design, promote their apps, and, thus, fit into the overall picture of the Chinese online landscape, which has coined the Chinese IT values. Furthermore, both websites promote food safety programs or corporate news like, e.g., KFC's debut in a documentary film regarding China's transformation of the food industry. Since the Chinese have a lack of trust towards most retailers and have no confidence in the sales system as there are complex and opaque market structures [8], both websites take care of the target group's values beyond IT. Although this example shows how important it is to orientate IS to the target group's cultural values, most software providers still struggle to consider cultural values when aiming to address new target groups with their IS. While Reinecke and Bernstein [9] showed a way how user interface designs can be automatically adapted according to cultural preferences, a method is lacking that also takes IT values beyond user interface preferences as well as general values of the target group into account, which, as shown in the example, can have an influence on IT design as well.

Against this backdrop, we aim to provide a method for culture-sensitive IS adaptation that takes the IS's values, the target group's perception towards IT as well as the group's general cultural values into consideration by grounding our method on the theory of IT-culture conflicts [2]. In this regard, we base our research endeavor on the following research question:

RQ: How should a method be designed to adapt IS to foreign cultural values?

To achieve our research aim, we follow the design science research approach, which constitutes a build- 
and-evaluate process, in order to rigorously design a practical relevant method for culture-sensitive adaptation of IS as an artifact [10, 11].

In particular, we followed the approach by Peffers et al. [10] for the design, demonstration, and evaluation of our method. Based on our insights from a multi-criteria demonstration and evaluation, we show the utility of our artifact, namely the method for culture-sensitive IS adaptation, in realistic as well as artificial settings to guide research and practice.

\section{Related Work and Theory Involved}

\subsection{Cultural Adaptation of IT artifacts}

When thinking about the development of IT artifacts for a specific user group, the presumably most popular method for designing an IS for a specific target group is the concept of the user-centered design [12]. By involving users during the whole design process of an IS [13], for example through different approaches of user engagement, such as user observations, usability tests, or prototyping, typically a higher degree of usefulness and usability is achieved [14]. With a special emphasis on user-centeredness, Ivari and Ivari [15] analyzed four system development methods to find out which dimension of usercenteredness they address. The results revealed that all development methods had a strong user and work focus, whereby the extent of user involvement varied between the methods. The target context's cultural values played a minor role in two methods, whereby only the contextual design method considers cultural issues by means of a cultural model, which captures policy and culture that limit the ways how work is done [16].

A sub-form of user-centered design relevant for the present paper is therefore the work on cultural adaptation of IT artifacts. The work of Reinecke and Bernstein [9], who connect culture and design preferences of user interfaces into the focus of their research, takes a broader perspective on culture. Following a design science approach, the authors developed an approach that enables IS to automatically adapt its interfaces to the preferences of the target user based on his or her cultural dimensions, which refer to the country scores promoted by Hofstede. In addition, the well-cited method from Shen et al. [17] provides a method for considering cultural adaptation processes with an iterative evaluation approach but without explicitly considering the complexity of cultural values. Besides these approaches, most IS research focuses on small areas in the field of culture and IS development like, e.g., culture's influence on requirements [1], the impact of individuals' cultural differences on the perception of usability [18, 19], or how IS development methods are deployed by varying organizational cultures [20]. Summing up, most approaches are mainly used to innovate and design new IS for a specific market, but do not consider explicitly how to address the complex relationship between culture and IT artifacts when adapting them to a target culture.

\subsection{IT-culture Conflict as a Kernel Theory}

To address the aforementioned issues of existing work on cultural adaptation of IT artifacts, we introduce the theory of IT-culture conflict as a kernel theory that guides our method presented in the next section. The theory attributes cultural values to IT and highlights IT's influence on culture, culture's influence on IT, and IT culture. By these means, the theory allows for a holistic understanding of the linkages between IT and culture [2]. In doing so, it provides a value-based perspective [21] on culture. As a result of an intensive literature analysis, Leidner and Kayworth state that IT is not free from values but, on the contrary, find that it is ,inherently symbolic and values laden " [2, p. 371]. In following Hofstede [22], Schein [23], and Trompenaars [24] in their observations that cultural aspects remain invisible for the most part, Leidner and Kayworth deduce that, unless faced with a counterculture, people remain unaware of their own culture. As it was stated that IT is indeed inherently values-laden, users of a certain IT artifact might come into conflict when starting to use it $[2,25]$. The proposed theory differentiates three types of conflicts that may occur as a result of two contradicting values: system, vision, and contribution conflicts. They are a result of contradicting IT values, group member values, and values embedded in a specific IT. Figure 1 illustrates the correlation between the different values and conflict types.

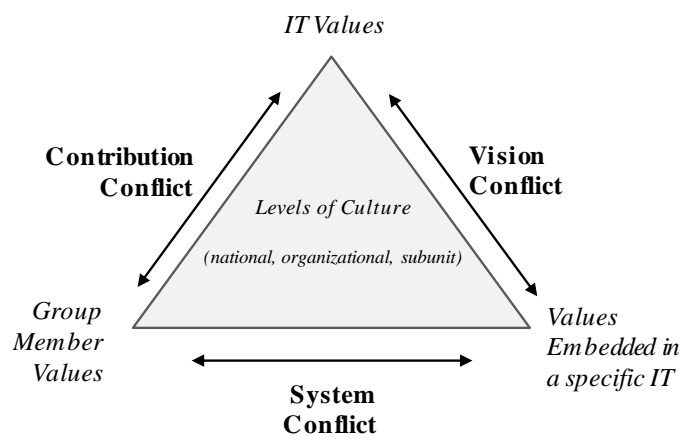

Figure 1. Theory of IT-culture conflict [2]

Considering this framework, beliefs about what is important to a group are referred to as group member values whereas values that a group of individuals attributes to IT are referred to as IT values, with the values embedded in a specific IT artifact complying 
with the work behavior that the IT aims to enable or prevent. The three types of conflict that may occur emerge from the intersection of national, organizational, and subunit culture [2]. The first type of conflict, the system conflict, occurs when the group member values conflict with the values that are included in a specific IT artifact that the group uses. A group of employees that has always been used to lecturer-centered software training, for example, might struggle to get used to a computer program that does not give any guidance or instructions to develop their qualifications. In this case, the common beliefs of the group about good training offerings is questioned by a specific IT artifact. The second type of conflict, the vision conflict, refers to the contradictions between the values that are embedded in a system and the IT values of the group. If game designers, for example, who see the sole purpose of smartphones in their hedonic characteristics have to install a mobile application that only serves training purposes, their IT values are challenged by the liability to use the smartphone for training purposes. The third type of conflict, the contribution conflict, refers to contradictions between the group members' individual values and the group's IT values. As an example, one might think about the usage of IT as a means for isolation in a group that in itself is relationshiporiented. Following these thoughts from Leidner and Kayworth [2], we therefore define cultural-sensitive adaptation of IS as the multi-level process of fitting the values embedded in IT to the values of group members and how group members perceive IT values in general.

\section{Method for Culture-sensitive Adaptation of IS}

For deriving the method for culture-sensitive adaptation of IS, we based the structure of the method on the typical IS development phases of analysis, design, and implementation [26] that are also prevalent in prior methods for culture-sensitive adaption [17]. As a kernel theory [27] we draw on the previously introduced theory of IT-culture conflict [2] that informs our method and the according steps to follow when adapting an IS in a culture-sensitive way.

The method itself, which is depicted in Figure 2, consists of five phases, namely: (1) structuring the initial situation, (2) IT-culture conflict analysis, (3) requirements, (4) design elements, and (5) implementation. Each of the proposed phases builds on previous phases and incorporates resulting artifacts, which are used as an input for the latter steps.

As a starting point, the unadapted IS as well as the target group (as an input for the overall method) are considered. The theory of IT-culture conflict plays a key role as a kernel theory throughout all process steps. In the beginning, the theory is used to structure the initial situation. In this regard, the three value types, which are differentiated by the theory, are specified to capture complex cultural relationships.

Based on value specifications, potential conflicts can be identified in a second step. The method focuses on conflicts that occur between contradicting values that are embedded in the IS and the group's perception towards IT in general as well as between the IS's values and the group's own cultural values beyond IT. In this context, we focus on potential system and vision conflicts, since our aim is to culturally adapt the IS, thus changing the values that are embedded in the IS with the intention to overcome potential conflicts. Since we expect no short-term effects of IT usage on a group member and the group's IT values, we omit the contribution conflict. In this regard, Leidner and Kayworth [2] also outline that IT management has more implications resulting from contribution conflicts than IT development.

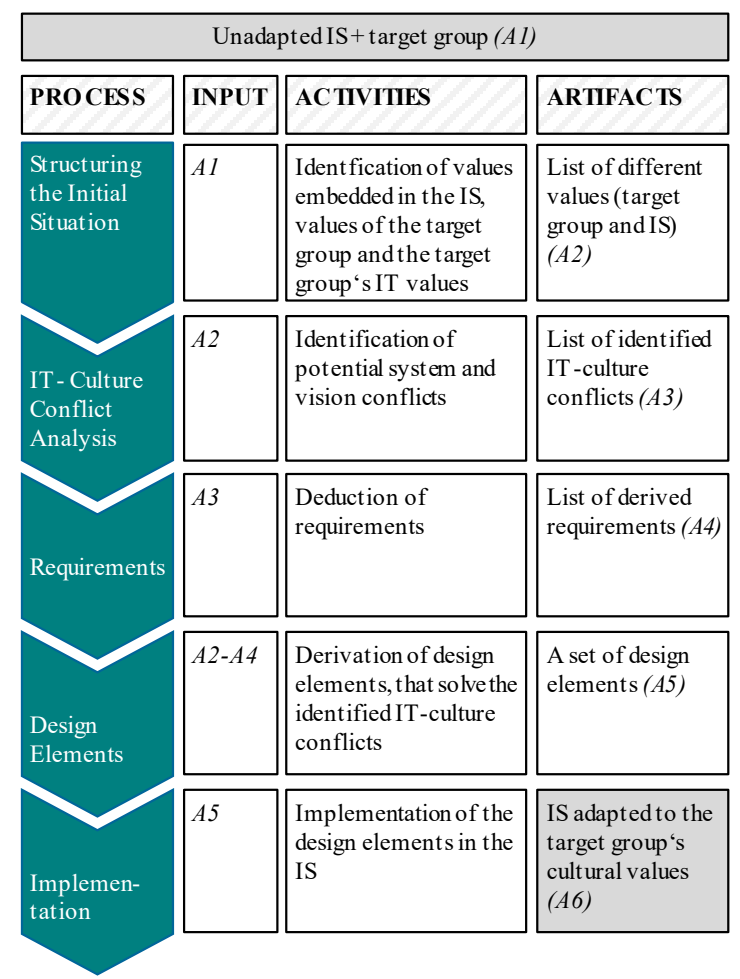

Figure 2. Method for cultural adaptation

As a third step, requirements are deduced from the identified system and vision conflicts. The requirements are addressed with design elements in a fourth step. To derive design elements that are appropriate for the IS target user group, the identified conflicts, and related value types, which are the resulting artifacts from steps 2 and 3 , are also 
considered as input. Finally, the design elements are being implemented in step 5 . The result obtained is the IS adapted to the target user group's cultural values. We outline the detailed application of the method and its steps in the next section, while also taking a multicriteria evaluation of the method into account.

\section{Demonstration and Evaluation}

With the following evaluations, we address the phases of demonstration and evaluation as depicted in the design science cycle [10] by testing the method for culture-sensitive IS adaptation in the field with multiple criteria. The described evaluation corresponds to the first design iteration of our design science endeavor. For our evaluation, we draw on the framework for evaluating DSR [28] and chose a formative ex-post evaluation approach $[29,28]$ that will help us to form the design of our method early in the development process. With the hereinafter described first evaluation and consequential insights, we aim to improve the method and to detect potential problems as an input for our second design iteration.

\subsection{Research Setting}

For the multi-criteria evaluation, the method for culture-sensitive IS adaptation was first applied in a DSR project to account for its real-world applicability. Second, we evaluated the method with a vast number of information systems engineering students as potential method users. The latter allowed us to gain distinct insights into the methods application behavior and the method outcomes, i.e., adapted IS. Moreover, we evaluated the method outcomes and adapted IS with an expert evaluation. These diverse and manifold insights will be used as a first input to revise the method and to start the second design iteration.

The unadapted IS for both evaluations constitutes a mobile learning application (MLA) that was developed in Germany. The MLA is intended to be introduced in Chinese vocational schools and should be used voluntarily by the students. Thus, it is important to adapt the IS according to the target group's perception towards IT as well as the group's general cultural values in order not to infringe on cultural values. Figure 3 shows the MLA.

Overall, the MLA operates with QR-codes that are attached to a car in the schools' repair shop. The MLA comprises two tasks related to 1) self-regulated acquisition of basic knowledge concerning car parts and 2) problem-solving. Both tasks are arranged as $\mathrm{QR}$-code scavenger hunts. In the first task type, distinct car parts are displayed, e.g., the headlight range adjustment, as depicted on the first screen. The user is requested to find the car part on the car and to scan the QR-code attached to it. Afterwards, information regarding the respective car part and a multiple-choice question, which is corrected after a solution attempt, is displayed (third screen). The task is repeated with different car parts.

Finally, after completion of all subtasks, an assessment is provided (fourth screen). In the second task type, distinct error descriptions are displayed, e.g., a poor road illumination, as shown in screen 5. First, the user is asked to reflect on possible problem causes, followed by a multiple-choice question. Afterwards, the user is requested to scan $\mathrm{QR}$-codes that are attached to car parts that might cause the problem. Having scanned the identified car parts, little boxes each presenting an error cause are filled and additional information regarding the fault analysis is displayed (sixth screen).

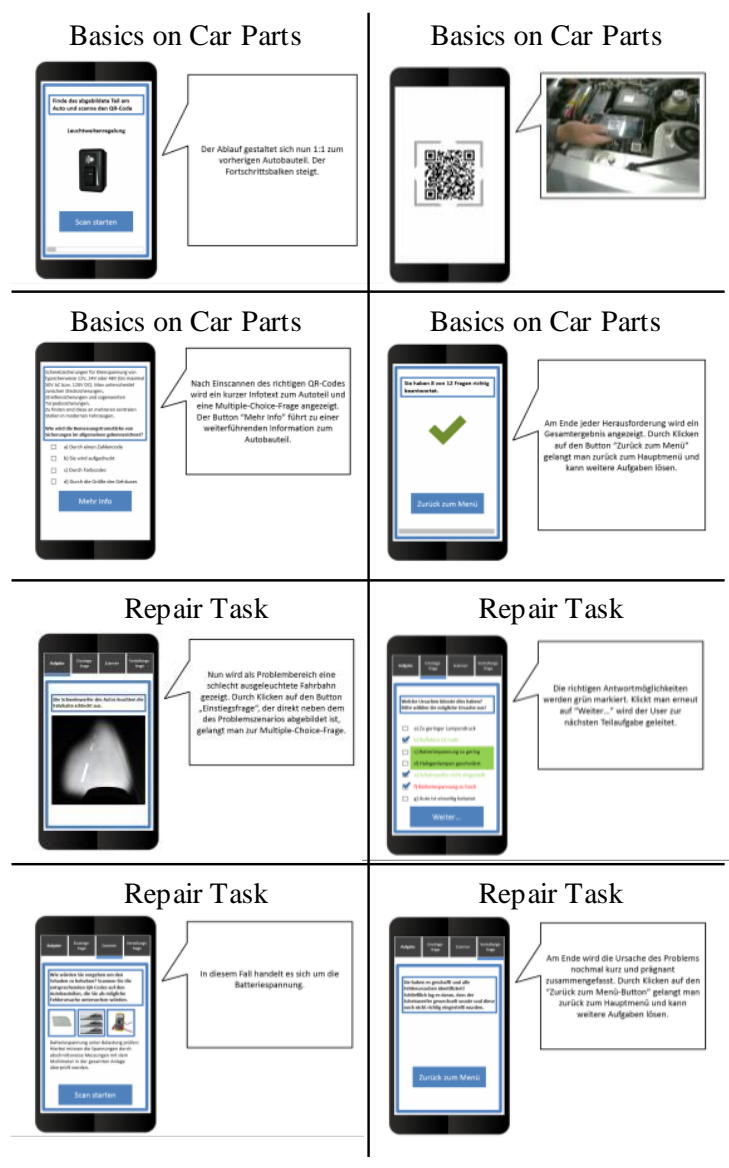

Figure 3. Unadapted IS

\subsection{Application and Evaluation of the Method in a Larger DSR Project}

The method got first applied in a larger DSR project $[30,31]$ to culturally adapt the MLA as outlined in Figure 3. The DSR project aimed to 
culturally adapt IS that is being transferred from Germany to China. We will briefly describe the method application in the following with one design element we implemented in the adapted MLA, while the complete DSR project comprised several other design elements for adapting the MLA to the Chinese user group.

Addressing the first phase namely structuring the initial situation, we analyzed the case and related literature regarding our target group trying to understand the distinct value types. As a result, we recognized that teachers play a very important role in Chinese schools. Thus, the habituation to lecturercentered lectures was recognized as a group member value (A2a). In contrast, the MLA is intended to be used in self-regulated ways, which was recognized as a value that is being embedded in the IT artifact (A2b). Addressing the second phase namely IT-culture conflict analysis, we identified a system conflict (A3) referring to the identified contradicting value types (A2a and A2b). In the third phase, we accordingly formulated the requirement "The MLA should offer a lecturer-centered learning approach", which was part of a larger list of requirements (A4). For the next phase, we used the formulated requirements as well as the insights, we gained from structuring the initial situation and derived a design element that solves the identified conflict. Thus, to address the fourth phase, we decided to implement a virtual character that gives the Chinese trainees guidance using the MLA (A5). Finally, in the sixth phase namely implementation, we adapted the MLA accordingly and inserted a virtual character (A6) to support self-regulated learning. To summarize, the method application led to unintuitive but effective design decisions such as focusing on selfregulated learning approaches instead of fostering collaborative learning, which would be the straightforward design decision when considering the rather collectivistic cultural values of China [32].

For the purpose of evaluating the method and its application, we rely on the outcomes of the actual MLA use. In this context, multiple experimental evaluations of the culturally adapted MLA in the target context (vocational schools in the Chinese provinces of Jiangsu as well as Anhui) showed that the adapted MLA leads to significantly improved learning outcomes (especially procedural knowledge as well as skill-based knowledge), compared to the not adapted MLA (references removed for double-blind review process).

\subsection{Application and Evaluation of the Method by Potential Method Users}

In the second evaluation step, we wanted to gain more generalizable insights concerning the method application and evaluation, while keeping potential method users in mind. The method was applied in the application and evaluation by students, who were trained in requirements engineering as well as systems design; thus, they are a suitable user sample for the method. Overall, the students' task was to culturally adapt the mobile learning application (MLA), as outlined in Figure 3, according to the cultural values of the target group of Chinese trainees in the automotive sector. Therefore, the students had to follow the method for culture-sensitive IS adaptation as depicted in Figure 2. The time between assignment and submission of documents was 11 days.

The students were provided with a mock-up that comprised screens and descriptions of the unadapted IS. Furthermore, they received information regarding the target group but were asked to search online for further information relevant for the adaptation purpose. In addition, the students received the method to structure their actions. The design adaptations were conducted by changing the screens and by adjusting the screen descriptions in the speech bubbles (Figure 3 ). Furthermore, the students could delete or add screens, if they considered deleting or adding an intermediate step in the task processing. In the task description, we emphasized that the students' job was not to adapt the IS according to the target group's preferences, but to solely address identified IT-culture conflicts and to strictly follow the provided method. The artifacts (A2-A6), as depicted in Figure 2, were required as a result and built the basis for evaluating the students' submissions.

The data collection took place in the course Introduction to Business and Information Systems Engineering. In total, 38 learners participated in the voluntary task of adapting the provided MLA to the target group of Chinese trainees in the automotive sector using the provided method. Table 1 depicts the demographics.

Besides these measures, we asked all students whether they have collected previous professional experience in IS development methodologies besides our training mentioned earlier. In this regard, almost all students were inexperienced in the field of IS development. Only one student specified a previous major in computer science. Thus, we assume all students were on a comparable level.

Following the approach of Riemenschneider et al. [33], who compared five theoretical models to explain software developer acceptance of methodologies, we asked the students who applied the method to fill out a post-test with a special emphasis on the acceptance of the method. Since our group of students does not comprise employed software developers, we did not test for social factors, e. g., the socials environment's 
influence on using the method, image, e. g., gaining prestige by applying the method and visibility, e. g., recognizing others applying the same method. Table 2 summarizes the findings. We adapted the measurement scales according to the approach by Riemenschneider [33]. The column "Source" indicates the origin of the scales before adaptation.

Table 1. Demographics

\begin{tabular}{|l|l|}
\hline Description & Value \\
\hline Gender & \\
Female ( $\mathrm{n}=16)$ & $42.1 \%$ \\
Male ( $\mathrm{n}=21)$ & $55.3 \%$ \\
No Answer $(\mathrm{n}=1)$ & $2.6 \%$ \\
\hline Age & \\
Mean (S.D. 3.28) & 24.53 Years \\
Median & 23 Years \\
Range & $20-31$ Years \\
\hline Major & \\
Industr. Engineering \& Economics (n=1) & $2.6 \%$ \\
Business Education (n=5) & $13.2 \%$ \\
Economic Law (n=1) & $2.6 \%$ \\
Business Administration (n=28) & $73.7 \%$ \\
No Answer $(\mathrm{n}=3)$ & $7.9 \%$ \\
\hline Semester & \\
Mean (S.D. 2.91) & 4.73 Semester \\
Median & 4.00 Semester \\
Range & $2-12$ Semester \\
\hline
\end{tabular}

As the results show, all constructs were rated above 4 , the neutral value of the seven-point Likert scale $(1=$ strongly disagree; $7=$ strongly agree) . Moreover, the results reveal that the method for culture-sensitive adaptation was perceived to be useful. Facilitating conditions, which refer to instructions to use the model, were also significantly rated above four, showing that the students did not have the feeling to miss instructions or guidance. Moreover, result demonstrability that refers to an understanding of the effects of applying the method was rated significantly above 4 .

Table 2. Software developer acceptance - results

\begin{tabular}{|l|c|c|c|}
\hline \multicolumn{1}{|c|}{ Construct } & Source & \multicolumn{2}{c|}{ Value } \\
\hline & & Mean & N \\
\hline Behavioral Intention & {$[34]$} & 4.200 & 35 \\
\hline Intention to Use & {$[35]$} & 4.224 & 35 \\
\hline Perceived Usefulness & {$[35]$} & 4.409 & 35 \\
\hline Perceived Ease of Use & {$[35]$} & 4.050 & 35 \\
\hline Voluntariness & {$[36]$} & 4.386 & 35 \\
\hline Compatibility & {$[36]$} & 4.224 & 32 \\
\hline Implementation Gap & {$[37]$} & 4.100 & 35 \\
\hline Facilitating Conditions & {$[38]$} & 4.544 & 34 \\
\hline Result Demonstrability & {$[36]$} & 4.421 & 34 \\
\hline
\end{tabular}

Moreover, we asked the students to give feedback regarding the task to culturally adapt the MLA. In this regard, one participant outlined: "following the method, I had a common thread I could use to orientate myself towards. This allowed my adjustments to be structured." Another student agreed with this view and mentioned: "an interesting practical task. [] The model has structured the approach well and thus allows a systematic adaptation." Overall, however, the task was not easy for the students and took up a lot of time, as most students had no prior knowledge in IS development and solely possess theoretical knowledge regarding established methods in IS development, like the waterfall or v-model. Some students reflected their task critically, thus mentioned: "at the beginning it was very complex to learn the necessary insights from the text. This has settled after an initial orientation." Concerning start difficulties, another participant also noticed: "for me, finding the conflicts was the biggest hurdle. When adapting the design, you could be creative." Besides problems with identifying the vision and system conflicts, one participant thought the implementation of the design elements to be difficult. In this manner, he annotated: "[...] I am wondering how many adjustments are too much and when do the adjustments [...] distract from learning [with the MLA]."

Besides these qualitative insights that we gained directly from our students, we also examined the artifacts (A2-A6), as depicted in Table 4, and included them in our evaluation. For our evaluation, the artifacts were examined by two independent raters, which are both experts in the fields of China and ITsupported learning.

Table 3. Evaluation by experts

\begin{tabular}{|l|l|l|l|l|l|}
\hline Evaluation Criterion & \multicolumn{2}{|l|}{ Rater 1 } & \multicolumn{2}{l|}{ Rater 2 } \\
\hline & Mean & N & Mean & N \\
\hline Quality of the Requirements & 3.84 & 38 & 4.47 & 38 \\
\hline Quality of the Design Elements & 3.58 & 38 & 3.72 & 36 \\
\hline Completeness of the Requirements & 3.18 & 38 & 3.29 & 38 \\
\hline Quality of the Targeting & 3.42 & 38 & 3.95 & 38 \\
\hline Resolution of IT-culture Conflicts & 3.16 & 38 & 3.54 & 37 \\
\hline $\begin{array}{l}\text { Intention to Reuse the Design } \\
\text { Elements }\end{array}$ & 3.13 & 38 & 3.89 & 36 \\
\hline
\end{tabular}

Before examining the results of the conducted cultural adaptation, the experts received information regarding the method, the descriptions that had been provided to the students, and the MLA. Moreover, the raters were informed about potential conflicts. While examining the assigned solutions with reference to the artifacts 
(A2-A6) the raters were encouraged to evaluate each artifact. In this regard, the experts were asked to rate the quality of the requirements, the quality of the design elements, the completeness of the requirements, the quality of the targeting, the resolution of IT-culture conflicts, and their intention to reuse the design elements on a 7-point Likert scale (1 $=$ strongly disagree; $7=$ strongly agree). Table 3 shows the ratings.

Table 4. Insights into the assigned solutions

\begin{tabular}{|l|l|}
\hline Positive Examples: & $\begin{array}{l}\text { User Interface that has been } \\
\text { adapted to the preferences of the } \\
\text { target group. } \\
\rightarrow \text { Target group might not use } \\
\text { the MLA when distracted by } \\
\text { its interface }\end{array}$ \\
\hline
\end{tabular}

Even though rater 2 evaluated the derived requirements better than 4 , the scale's reference value, both ratings indicate that the method for culture- sensitive adaptation still needs refinement to deliver satisfactory results for satisfying experts. Nonetheless, as rater 2 highlighted, the quality of the requirements tends to be satisfactory and, therefore, highlights the value of deriving requirements through our method for novices in cultural adaption.

To provide a more complete picture of the culturesensitive adaptation, Table 4 shows exemplary pictures of the students' assigned culturally adapted MLA using the method for culture-sensitive IS adaptation. Overall, many students followed similar directions when describing the target groups' values. However, the step of culture identification leads the students to diverse conflicts and, thus, requirements. Furthermore, similar requirements were transformed into various design elements. Reviewing the results, we discovered design elements that were derived by identified conflicts, but the selection of the design elements, however, was so unfortunate that the design elements themselves caused further conflicts.

To quote an example, many assigned solutions comprised rankings and profiles to adapt the MLA according to the target group's IT values. Referring to this, Chinese teenagers predominantly use their smartphones for gaming purposes; asking them to also use their smartphones for learning purposes might cause a conflict. However, the integration of public rankings or profiles that can be tracked by the teacher might increase the trainees' pressure to solve tasks. Thus, trainees with poorer results would probably stop continuing using the MLA voluntarily. Another assigned adapted MLA integrated an exchange function that allows the trainees to exchange with experts, disregarding the fact that Chinese culture is characterized by a strong power distance [39]. Besides these negative examples, the method also leads to positive examples of cultural adaptation, e. g., UI adaption, integration of videos, pictures, and game elements as well as the integration of avatars. All examples are illustrated in Table 4.

\section{Discussion and Implications}

In our study, we designed a method for culturesensitive IS adaptation by means of the theory of ITculture conflicts [2], which we applied as a kernel theory [27]. We followed the design science approach [10], which constitutes a build-and-evaluate process, to rigorously design the method as an artifact.

Considering our RQ, we propose the conceptual thoughts, implementation results, and evaluation insights of our design science approach. We chose a formative ex-post evaluation approach [28, 29] and tested our artifact in different research settings including a naturalistic and outcome-oriented setting, 
as well as an artificial setting that was concerned with the process of applying the method and how the potential developers experienced the application of the method. Thus, we had the method applied by a vast number of students, who were previously trained in requirements engineering as well as systems design. Furthermore, we had the method's artifacts evaluated by experts to also consider the quality of the outcomes and to identify relevant points for optimization.

Regarding our design, we draw on the kernel theory of IT-culture conflicts, which allows us to identify and differentiate cultural values that might cause conflicts when contradicting with values of a newly integrated IS. In contrast to other approaches for cultural adaptation, e. g., cultural adaptation of user interfaces [9], the theory allows us to also take into account the values of the IS. Based on conflict identification, we identify a real need for changes, since IS that does not coincide with the users' values are likely to be rejected. The results of our evaluation reveal that the method for culture-sensitive IS adaptation enables the systematic culture-sensitive adaptation to create feasible results for developing culture-sensitive design solutions for IS, i.e., shown through the improvement of IT outcomes when utilizing the method in a large design science research project.

Concerning the user evaluation, the participants' behavioral intention to use as well as the perceived usefulness of the method were positively rated, showing that the participants comprehend the method's purpose and like the idea of identifying and resolving conflicts. This impression is reinforced by the participants' clear perception of the results and consequences of applying the method. Referring to the method's complexity, the perceived ease of use was rated low. In this context, the construct implementation gap also reveals that participants experienced a gap between their existing skills and the knowledge required by the method. Summarizing the results of these two constructs, we see a need for improvements in terms of increasing the method's usability. In this regard, guiding questions may lead the user through the adaptation steps. Moreover, guiding questions could make the elicitation of the target group's cultural values as well as the IS' values easier. Besides these findings, we also recognized a linking problem between the steps of IT-culture conflict identification, formulation of the requirements, and the derivation of design elements. Since the design elements are used to change the values embedded in the IS and thus to resolve the identified conflict, we consider omitting the interim step of requirement formulation. The formulation of requirements is a standard procedure in IS development [26]; however, other design methods do not have a preceding step of conflict identification, which might substitute the requirement analysis. Besides the linking problem, we imagine that the omission of requirements might also resolve the problem regarding the selection of the design elements that cause further conflicts since we expect that more information regarding the target group's values flows into the subsequent steps. Besides these approaches, a database with design characteristics for each country might have helped the participants to select appropriate design elements. In this regard, Nordhoff et al. [40] hold out the prospect of analyzing countryspecific design elements beyond image metrics, which we could use as a basis for providing help in the selection of design elements.

Our paper offers several contributions to theory. First, we expand the understanding of the theory of ITculture conflicts [2], which significantly influenced the design of our method for culture-sensitive IS adaptation as a kernel theory [27]. Second, we contribute to the exploration of cultural characteristics when adapting IS according to the cultural values of the target group. Applying the design science methodology, we also contribute to IS design science research with a new solution for the acknowledged problem of cultural adaptation [41]. Notwithstanding, we emphasize that our designed method still needs improvement to make a thorough contribution.

From a practical perspective, we provide with our method step-by-step guidance to practitioners into how they can adapt IS according to foreign cultural values. Especially when considering the outlined case of the introduction, conflict analysis of IT artifacts helps practitioners to avoid problematic and maybe embarrassing IT implementations in foreign cultures. Helping to improve the value creation of IS, we, therefore, contribute to service systems engineering by explicitly considering the context of services [3].

\section{Limitations and Future Research}

Our design of a method for culture-sensitive IS adaptation is not without limitations. While the theory of IT-culture conflict comprises distinct levels of cultural applicability, we could not evaluate in student-based evaluation to acknowledge cultural values on a national, organizational, and subunit level. However, we note that this shortcoming was taken care of in the evaluation in the large design science research project where explicitly multi-level criteria were considered for the conflict identification. In this context we acknowledge that the method was tested by students within the scope of a lecture regarding business and information systems engineering; thus, 
we remark that professional IS developers might have applied the method differently, which leads to distinct results as shown in the field evaluation. Moreover, the raters were experts in the fields of China and ITsupported learning but had no specific expertise in the field of IS development and consequently could not evaluate the assigned results from this perspective. In this regard, an evaluation with real users in a real setting might expand our insights and lead to innovative ideas, measures, and aspects of method adaptation. To gain further insights into the problemsolving processes of IS developers [43], the thinkaloud technique could be a suitable instrument for field studies in empirical software engineering [42].

\section{Conclusion}

With this paper, we provide a design and evaluation of a theory-motivated method for culturesensitive adaptation of IS that draws on the theory of IT-culture conflict. From a methodological perspective, we followed the design science approach to rigorously design and evaluate the method, which enables in developing culture-sensitive solutions for IS. We contribute to practice by guiding how to culturally-sensitive adapt IS according to foreign cultural values. As a theoretical contribution, we contribute to the exploration of culture in IS development.

\section{Acknowledgements}

We thank Sissy-Josefina Ernst for providing the first version of this work that served as the basis for the paper. The first author acknowledges funding from the Basic Research Fund (GFF) of the University of St. Gallen.

\section{References}

[1] Tuunanen, T. and I.-T. Kuo, "The effect of culture on requirements: A value-based view of prioritization", European Journal of Information Systems, 24(3), 2015, pp. 295-313.

[2] Leidner, D.E. and T. Kayworth, "Review: A Review of Culture in Information Systems Research: Toward a Theory of Information Technology Culture Conflict", MIS Quarterly, 30(2), 2006, pp. 357-399.

[3] Böhmann, T., J.M. Leimeister, and K. Möslein, "Service Systems Engineering: A Field for Future Information Systems Research", Business \& Information Systems Engineering, 6(2), 2014, pp. 73-79.

[4] Walsh, I., "A strategic path to study IT use through users' IT culture and IT needs: A mixed-method grounded theory",
The Journal of Strategic Information Systems, 23(2), 2014, pp. $146-173$.

[5] Alavi, M., T.R. Kayworth, and D.E. Leidner, "An Empirical Examination of the Influence of Organizational Culture on Knowledge Management Practices", Journal of Management Information Systems, 22(3), 2005, pp. 191224.

[6] Wagner, E.L. and S. Newell, "'Best' for whom?: The tension between 'best practice' ERP packages and diverse epistemic cultures in a university context", The Journal of Strategic Information Systems, 13(4), 2004, pp. 305-328.

[7] He, X., "The ERP challenge in China: A resource-based perspective", Information Systems Journal, 14(2), 2004, pp. 153-167.

[8] Zhu, R., "Understanding Chinese Consumers", Harvard Business Review, 2017.

[9] Reinecke, K. and A. Bernstein, "Knowing what a User Likes: A Design Science Approach to Interfaces that Automatically Adapt to Culture", MIS Quarterly, 37(2), 2013, pp. 427-453.

[10] Peffers, K., T. Tuunanen, M.A. Rothenberger, and S. Chatterjee, "A design science research methodology for information systems research", Journal of Management Information Systems, 24(3), 2007, pp. 45-78.

[11] Hevner, A.R., S.T. March, J. Park, and S. Ram, "Design Science in Information Systems Research", MIS Quarterly, 28(1), 2004, pp. 75-105.

[12] Norman, D.A. and S.W. Draper, eds., User centered system design. New perspectives on human-computer interaction, L. Erlbaum Associates Inc. Hillsdale, Hillsdale, NJ., 1986.

[13] Petrelli, D., M. Beaulieu, M. Sanderson, G. Demetriou, P. Herring, and P. Hansen, "Observing users, designing clarity: A case study on the user-centered design of a crosslanguage information retrieval system", journal of the American Society for Imformation Science and Technology, 55(10), 2004, pp. 923-934.

[14] Mao, J.-Y., K. Vredenburg, P.W. Smith, and T. Carey, "The state of user-centered design practice", Communications of the ACM, 48(3), 2005, pp. 105-109.

[15] Iivari, J. and N. Iivari, "Varieties of user-centredness: An analysis of four systems development methods", Information Systems Journal, 21(2), 2011, pp. 125-153.

[16] Beyer, H. and K. Holtzblatt, Contextual design: Defining customer-centered systems, Morgan Kaufmann, San Francisco, Calif., 1998.

[17] Shen, S.-T., M. Woolley, and S. Prior, "Towards culture-centred design", Interacting with Computers, 18(4), 2006, pp. 820-852.

[18] Downey, S., R.M. Wentling, T. Wentling, and A. Wadsworth, "The Relationship between National Culture and the Usability of an E-learning System", Human Resource Development International, 8(1), 2005, pp. 47-64. 
[19] Alexander, R., N. Thompson, T. McGill, and D. Murray, "The Influence of User Culture on Website Usability", International Journal of Human-Computer Studies, 2021, p. 102688.

[20] Iivari, J. and M. Huisman, "The Relationship between Organizational Culture and the Deployment of Systems Development Methodologies", MIS Quarterly, 31(1), 2007, pp. 35-58.

[21] Schein, E.H., "Coming to a New Awareness of Organizational Culture", Sloan Management Review, 25(2), 1984, pp. 3-16.

[22] Hofstede, G., Culture's consequences: International differences in work-related values, Sage Publications, Inc, 1980.

[23] Schein, E.H., "How Culture Forms, Develops and Changes", in Gaining Control of the Corporate Culture, R.H. Kilmann, M.J. Saxton, and R. Serpa, Editors. 1985. JosseyBass: San Francisco.

[24] Trompenaars, F., "Resolving International Conflict: Culture and Business Strategy", Business Strategy Review, 7(3), 1996, pp. 51-68.

[25] Koch, H., D.E. Leidner, and E.S. Gonzalez, "Digitally enabling social networks: resolving IT-culture conflict", Information Systems Journal, 2013, pp. 501-523.

[26] Tsui, F., O. Karam, and B. Bernal, Essentials of Software Engineering, 4th edn., Jones and Bartlett Learning, Burlington, 2016.

[27] Gregor, S., "The nature of theory in information systems", MIS Quarterly, 30(3), 2006, pp. 611-642.

[28] Venable, J., J. Pries-Heje, and R. Baskerville, "FEDS: a Framework for Evaluation in Design Science Research", European Journal of Information Systems, 25(1), 2016, pp. 77-89.

[29] Sonnenberg, C. and J. vom Brocke, "Evaluation Patterns for Design Science Research Artefacts", in Proceedings of the European Design Science Symposium (EDSS), M. Helfert and B. Donnellan, Editors. 2012. Springer Berlin Heidelberg: Dublin.

[30] Ernst, S.-J., A. Janson, M. Söllner, and J.M. Leimeister, "It's about Understanding Each Other's Culture - Improving the Outcomes of Mobile Learning by Avoiding Culture Conflicts", ICIS 2016 Proceedings, 2016.

[31] Janson, A., M. Thiel de Gafenco, J. Klusmeyer, and J.M. Leimeister, "Aufbau und Ablauf des kuLtig-Projektes", in Export beruflicher Aus- und Weiterbildung: Entwicklung und Evaluation kultursensitiver Lerndienstleistungen am Beispiel China, J.M. Leimeister and J. Klusmeyer, Editors. 2020. Springer Fachmedien Wiesbaden: Wiesbaden.

[32] Hofstede, G., "Cultural differences in teaching and learning", International Journal of Intercultural Relations, 10(3), 1986, pp. 301-320.

[33] Riemenschneider, C.K., B.C. Hardgrave, and F.D. Davis, "Explaining Software Developer Acceptance of
Methodologies: A Comparison of Five Theoretical Models", IEEE Trans. on Software Engineering, 28(12), 2002, pp. 1135-1145.

[34] Venkatesh, V. and F.D. Davis, "A Theoretical Extension of the Technology Acceptance Model: Four Longitudinal Field Studies", Management Science, 46(2), 2000, pp. 186-204.

[35] Davis, F.D., "Perceived Usefulness, Perceived Ease of Use, and User Acceptance of Information Technology", MIS Quarterly, 13(3), 1989, pp. 319-340.

[36] Moore, G.C. and I. Benbasat, "Development of an Instrument to Measure the Perceptions of Adopting an Information Technology Innovation", Information Systems Research, 2(3), 1991, pp. 192-222.

[37] Chau, P.Y.K., "An empirical investigation on factors affecting the acceptance of CASE by systems developers", Information \& Management, 30(6), 1996, pp. 269-280.

[38] Thompson, R.L., C.A. Higgins, and J.M. Howell, "Personal Computing: Toward a Conceptual Model of Utilization", MIS Quarterly, 15(1), 1991, pp. 125-143.

[39] https://www.hofstede-insights.com/country/china/, accessed 8-28-2018.

[40] Nordhoff, M., T. August, N.A. Oliveira, and K. Reinecke, "A Case for Design Localization: Diversity of Website Designs in 44 Countries", in Proceedings of the 2018 CHI Conference on Human Factors in Computing Systems - CHI '18, R. Mandryk, M. Hancock, M. Perry, and A. Cox, Editors, the 2018 CHI Conference, Montreal QC, Canada, 21.04.2018 - 26.04.2018. 2018. ACM Press: New York, New York, USA.

[41] Gregor, S. and A.R. Hevner, "Positioning and Presenting Design Science Research for Maximum Impact", MIS Quarterly, 37(2), 2013, p. 337.

[42] Lethbridge, T.C., S.E. Sim, and J. Singer, "Studying Software Engineers: Data Collection Techniques for Software Field Studies", Empirical Software Engineering, 10(3), 2005, pp. 311-341.

[43] Dickhaut, E., A. Janson, and J.M. Leimeister, "Codifying Interdisciplinary Design Knowledge Through Patterns - The Case of Smart Personal Assistants", in Designing for Digital Transformation. Co-Creating Services with Citizens and Industry, S. Hofmann, O. Müller, and M. Rossi, Editors. 2020. Springer International Publishing: Cham. 